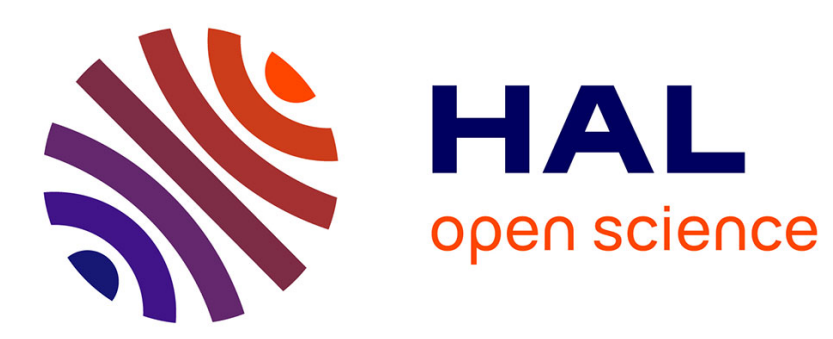

\title{
Observing air quality over the city of Nantes by means of Landsat thermal infrared data
}

\author{
Lucien Wald, Jean-Michel Baleynaud
}

\section{To cite this version:}

Lucien Wald, Jean-Michel Baleynaud. Observing air quality over the city of Nantes by means of Landsat thermal infrared data. International Journal of Remote Sensing, 1999, 20 (5), pp.947-959. hal-00356181

\section{HAL Id: hal-00356181 \\ https://hal.science/hal-00356181}

Submitted on 26 Jan 2009

HAL is a multi-disciplinary open access archive for the deposit and dissemination of scientific research documents, whether they are published or not. The documents may come from teaching and research institutions in France or abroad, or from public or private research centers.
L'archive ouverte pluridisciplinaire HAL, est destinée au dépôt et à la diffusion de documents scientifiques de niveau recherche, publiés ou non, émanant des établissements d'enseignement et de recherche français ou étrangers, des laboratoires publics ou privés. 


\title{
OBSERVING AIR QUALITY OVER THE CITY OF NANTES BY MEANS OF LANDSAT THERMAL INFRARED DATA
}

\author{
L. Wald (1), J.-M. Baleynaud (2)
}

(1) Groupe Télédétection \& Modélisation, Centre d'Energétique, Ecole des Mines de Paris, BP 207, 06904 Sophia Antipolis cedex, France

(2) Département Systèmes Energétiques et Environnement, Ecole des Mines de Nantes, 4 rue Alfred Kastler, 44070 Nantes cedex 03, France

\begin{abstract}
This article investigates the potentials of satellite-made observations for the mapping of air quality parameters. Ground measurements of black particulates, sulphur dioxide and other pollutants have been measured in the city of Nantes and are compared to coincident Landsat TM6 data. It is found that the amount in black particulates is highly correlated to the apparent temperature observed by satellite. Some of the possible mechanisms for this correlation are investigated. The influence of the pixel size on this correlation is discussed in view of previous studies. Preliminary explanations are given. The mapping of the spatial distribution of the black particulates is possible from remotelysensed data. It is not very accurate and possible improvements are discussed. Finally, it is shown that pollution level should be taken into account in any use of satellite data for urban area classification purposes.
\end{abstract}

\section{INTRODUCTION}

Atmospheric pollution in cities is receiving more and more attention. A spectacular case occurred in the Arabian Gulf in 1991. In February 1991, nearly 650 oil wells in Kuwait were set on fire. As a result smoke plumes have obscured the sky south of Kuwait due to prevailing winds, and have thus reduced the solar light impinging at ground level. As an example, the relative monthly solar radiation in Bahrain, $600 \mathrm{~km}$ south-east of Kuwait, was reduced by up to $20 \%$ from April to July 1991 (Alnaser, 1995). This event has consequences on human health which will not be fully understood for several years yet. Beyond such major cases, chronic pollution exists in urban atmosphere with strong, but usually not spectacular, impacts on human health, human comfort and daily life. For example, authorities are restricting circulation of private cars more and more often in large cities because high levels of air pollution are reached. Medical studies tend to demonstrate that breathing diseases may be linked to peaks in pollution and that old persons and very young children are most affected (see e.g., McMichael et al. 1996). It is therefore one of the major issues to be tackled by our society, including research and politic al communities.

Networks of instruments have been established in major cities. They are composed of a few measuring stations and are a means for alert. They are also a valuable tool for researchers and planners who are interested in knowing how the air quality evolves according to the various parameters affecting it. However air quality is highly variable within a city. It is a function of the intensities of the air advection and turbulent diffusion around the pollution sources, but not uniquely so. These sources may have a wide distribution, as is the case for exhaust gas of vehicle motors. Some streets are highly ventilated, others are not. The ventilation is also a function of the wind direction; it follows that a street may be occasionally ventilated or not. Because they are widely distributed, the measuring stations do not allow a proper mapping of the pollution. However mapping capability is strongly required because of the major following benefits:

- it provides a complete survey of the city

- it shows the major sources of pollution together with their distribution

- it indicates where efforts should be preferably made to decrease the level of pollution

- it helps further analysis in showing relationships that might exist between city features (taken in the broad sense) and air pollution distribution

- it serves as a basis for re-enforcing the sampling strategy by moving some stations to appropriate locations, or adding some or possibly removing some. 


\section{BACKGROUND}

Routine observations made by the environmental satellites are certainly a valuable aid in improving the actual methods of mapping. Some studies have been made using such data. Most of them deal with the urban heat island (see e. g., Dousset 1991, Dousset et al. 1993, Henry et al. 1989, Le 1993, Kim 1992, Price 1979 Quattrochi and Ridd 1994, Roth and Oke 1989). They mostly consist of mapping the radiance sensed by thermal instruments onto a map of the city. Such instruments are intended to measure the temperature of the surface of the objects. The heat urban islands then appear as hot anomalies with respect to the temperatures of the remainder of the city. These urban heat islands are not an indicator of the air pollution, but do favour it. Urban sink is a less common phenomenon and consists of an urban are cooler than the surrounding rural area. It has also been observed by satellite (Carnahan and Larson 1990).

Other studies specifically deal with the possible relationships between the air pollution and satellite images. Sifakis $e t$ al. (1992) use two Landsat images taken at a date of non-pollution and at the date of a pollution episode. Temperature maps (actually radiance maps) are made for both dates and compared. Large decreases in temperature are related to the appearance of a pollution layer over some parts of the city. Images taken in the visible range are also processed, but a different way. Anomalies in contrast, i.e. abrupt changes in spatial gradients, are mapped, but for the man-made changes, and if the time-lag between both images is not too large, then these changes are related to the appearance of the pollution layer. Actually such an approach can be used with any sensor being sensitive to a change in atmospheric absorption-scattering of the reflected (visible to near-infrared) or emitted radiation (thermal infrared). This study has been successful in mapping the extension of the pollution layer. However it presently has limitations, i.e. no link has been established with the actual level of pollution; such a mapping cannot be made at fine-scale and no accuracy of the pollution level can be assessed at the pixel level.

Other studies seek for a relationship between satellite data and ground-based measurements. These satellite data are radiances observed by the sensor in thermal infrared band(s). These radiances are a function of the temperature and emissivity of the surface and also of the optical properties of the atmospheric column above the pixel and its surroundings. Most of the bodies of interest have an emissivity larger than 0.8 (e.g. Gaussorgues 1989). In that case, for the spectral band of interest, the emission by the surface is the most important phenomenom. The radiance emitted by the atmosphere towards the sensor after its reflection on the surface accounts for approximately $10 \%$ of the total radiance and may be neglected. Accordingly in a first approximation the temperature $T_{\text {sat }}$ observed by the space-borne sensor can be written:

$$
\mathrm{T}_{\mathrm{sat}}=\tau \varepsilon \mathrm{T}_{\mathrm{surf}}+\mathrm{T}_{\mathrm{atm}}
$$

where $T_{\text {surf }}$ is the surface temperature, $\varepsilon$ the surface emissivity, $\tau$ the transmission factor of the atmosphere, and $T_{\text {atm }} a$ weighted-average temperature modelling the emission of the atmosphere itself. This equation should actually be written in radiances. However as long as a limited range of temperature is concerned, the Planck function can be approximated by a linear function and this equation holds. From this equation, it appears that a decrease in the atmospheric transmission factor as caused by the appearance of a pollution layer (more absorption and scattering) results in a decrease in $T_{\text {sat }}$. This decrease may be significant enough to be sensed by space-borne sensors such as Landsat TM, the sensitivity of which is $0.5^{\circ} \mathrm{C}$. This was experienced and discussed by Mc Lellan as early as 1973 . Actually the change would also have an impact on the radiance emitted by the atmosphere (modelled by $T_{a t m}$ ) but the impact is negligible in a first approximation because the pollution layer is usually of very limited vertical extension and $T_{\text {atm }}$ results from an integration over the entire atmospheric column.

Some studies have been made along these lines. They make use of images acquired by the Landsat TM sensor. This sensor has several bands (TM1-7), all of them but one are in the visible or near-infrared range with a spatial resolution of $30 \mathrm{~m}$. The thermal infrared band (TM6) has a spatial resolution of $120 \mathrm{~m}$, four times less than that of the other bands. The sensor outputs in this band are calibrated in radiance by the means of in-board calibration systems. These radiances are in turn transformed into apparent temperatures at the top of the atmosphere. It should be noted that the digital numbers output from TM6 are opposite to the apparent temperatures: the colder a given surface, the smaller the apparent temperature, and the larger the digital count in TM6. Landsat images are acquired at 1030 mean solar time, in clear sky conditions. This hour is rather suitable for this kind of investigation. Strong insolation has not yet 
warmed the objects too much, but the night cooling has already passed and objects within the cities tend to have rather similar surface temperatures.

Poli et al. (1994) study the relationship between a map of apparent temperature of Rome (Italy) and the total particulate matter suspended in the air (PTS) in the winter season. The PTS as well as the sulphur dioxide (SO2) were measured at five locations and are daily sums. The particulate matter is assumed to be a significant tracer of the atmospheric pollution as well as a good indicator of the air quality. Noticeable levels of pollution have been observed for the day under concern (table 1). Poli et al. find a strong negative correlation (-0.97) between the satellite-derived temperature (see column 4 in table 1) and the PTS. Confidence level for this coefficient is well above $95 \%$. On the contrary (table 1), the correlation between the sulphur dioxide (SO2) and satellite-derived temperature is weak and there is no significant relationship.

\begin{tabular}{|c|c|c|c|}
\hline Station name & $\mathrm{SO} 2\left(\mu \mathrm{g} / \mathrm{m}^{3}\right)$ & PTS $\left(\mathrm{mg} / \mathrm{m}^{3}\right)$ & $\begin{array}{c}\text { Apparent temperature } \\
\text { (arbitrary units) }\end{array}$ \\
\hline Fermi & 125 & 157.8 & 75 \\
\hline Magna Grecia & 91 & 136.3 & 77 \\
\hline Arenula & 67 & 87.4 & 78 \\
\hline Preneste & 35 & 179.0 & 80 \\
\hline Francia & 24 & 39.8 & 80 \\
\hline
\end{tabular}

Table 1. Pollutants values reported for Roma by Poli et al. (1994). Winter season. A step of 1 in satellite measurements (apparent temperature) corresponds approximately to $0.5^{\circ} \mathrm{C}$.

Even weaker correlation with SO2 was observed by Brivio et al. (1995) for the urban area of Milan (Italy). These authors use apparent temperatures with a pixel of $1 \mathrm{~km}$ in size, observed by the AVHRR sensor aboard the NOAA satellites. Three images were processed: 12, 13 and 14 February 1993. The correlation with the PTS is also weak, and it may be explained by the very large size of the pixel.

Finzi and Lechi (1991) analysed two Landsat images of Milan and compared them. The first one is dated 20 January 1983 and was taken during clean conditions. The second is dated 27 January 1986 when pollution reached critical levels. Though the SO2 itself is transparent in the thermal infrared (IR) band, it is usually associated with NOx particulates and aerosol, giving a combined effect of opacity within the atmosphere. Hence the authors considered the $\mathrm{SO} 2$ concentration as a good tracer of the global urban air pollution level. Ten ground stations were considered, each supplying SO2 concentrations every 30 minutes. Prior to the analysis, Finzi and Lechi have aggregated the TM6 pixels into large polygons, one per station, covering the city. For the unpolluted day, the correlation coefficient between the SO2 and the satellite apparent temperatures is very low (0.48). For the polluted day, this coefficient is 0.84 . However, a close examination of their findings (their figures 7 and 8 , with the units normalised), shows that these results are partly contradictory and that no definite conclusion can be drawn. As for Brivio et al., the use of large polygons may partly explain the results, given the large variability in space and time of the pollutants.

To summarise, only a few studies have been made on the correlation between satellite measurements in thermal infrared and air quality parameters. They partly conflict regarding SO2. This study adds to the presently limited evidence on such correlation. Then it discusses the possible exp lanation of these correlations.

\section{DESCRIPTION OF THE STUDIED AREA}

Nantes is a large city, located in Western France, along the Loire River, $16 \mathrm{~km}$ from the estuary which is itself approximately $50 \mathrm{~km}$ in length. Geographical co-ordinates are $47.23^{\circ} \mathrm{N}$ and $1.55^{\circ} \mathrm{W}$. It comprises about 470000 inhabitants. Nantes has been a very active harbour for several centuries, with much trade with Africa and America. The ocean is only $54 \mathrm{~km}$ to the West and therefore influences the climate, which is quite mild. Except for a oil refinery $20 \mathrm{~km}$ to the West, Nantes has little polluting industry. Pollution is mostly due to vehicle traffic (Loirestu'Air, 1995).

Loirestu'Air is the company in charge of measuring air quality in Nantes and vicinity. In May 1992, 14 measuring stations were located within the urban area, 12 for the city itself. Among them, three were measuring nitrogen dioxide 
(NO2) and four sulphur dioxide (SO2), as indicated in table 2. The measurements are well as the implementation of the network follow the standards AFNOR NFX 43-005 laid down in 1977. Most of these stations are measuring the background air quality: they are located at about $100 \mathrm{~m}$ of a street with little traffic. Others are located along the major traffic axes. Other measured parameters are black particulates (BP), nitrogen monoxide (NO), and strong acidity (AF). The BP are daily sums, while for the others, measurements are made every $15 \mathrm{~min}$ and averaged over this period. A daily mean value is provided by averaging the measurements over the day. Correlation between the various parameters is shown in table 3. Correlations between the daily averages are strong, they are usually lower between instantaneous measurements and daily averages. Air quality parameters are strongly variable in time, either because of the high variability of the traffic, or the volatility and chemical transformations of some pollutants. Correlation between the various parameters and the BP is usually high. Hence the BP can be considered as representing the pollution level for this day. The BP differs significantly from the PTS. The BP measures the density of particles having a diameter larger than $5 \mu$. The threshold for the measurement of the PTS is variable and it is not always a reliable indicator of pollution.

\begin{tabular}{|c|c|c|c|c|c|c|c|c|c|}
\hline & BP & SO2 & SO2 day & NO2 & NO2 day & NO & NO day & AF & AF day \\
\hline $\begin{array}{c}\text { Number } \\
\text { of values }\end{array}$ & 12 & 4 & 4 & 3 & 3 & 3 & 3 & 9 & 9 \\
\hline Type & Daily sum & $15 \mathrm{~min}$ & $\begin{array}{c}\text { Daily } \\
\text { average }\end{array}$ & $15 \mathrm{~min}$ & $\begin{array}{c}\text { Daily } \\
\text { average }\end{array}$ & $15 \mathrm{~min}$ & $\begin{array}{c}\text { Daily } \\
\text { average }\end{array}$ & 15 min & $\begin{array}{c}\text { Daily } \\
\text { average }\end{array}$ \\
\hline $\begin{array}{c}\text { Range for } \\
\text { the day }\end{array}$ & $\begin{array}{c}\mathrm{k}-34 \\
\mathrm{~g} / \mathrm{m}^{3}\end{array}$ & $\begin{array}{c}8-29 \\
\mu \mathrm{g} / \mathrm{m}^{3}\end{array}$ & $\begin{array}{c}4-16 \\
\mu \mathrm{g} / \mathrm{m}^{3}\end{array}$ & $\begin{array}{c}26-101 \\
\mu \mathrm{g} / \mathrm{m}^{3}\end{array}$ & $\begin{array}{c}23-79 \\
\mu \mathrm{g} / \mathrm{m}^{3}\end{array}$ & $\begin{array}{c}7-93 \\
\mu \mathrm{g} / \mathrm{m}^{3}\end{array}$ & $\begin{array}{c}5-57 \\
\mu \mathrm{g} / \mathrm{m}^{3}\end{array}$ & $\begin{array}{c}0-16 \\
\mu \mathrm{g} / \mathrm{m}^{3}\end{array}$ & $\begin{array}{c}0-18 \\
\mu \mathrm{g} / \mathrm{m}^{3}\end{array}$ \\
\hline
\end{tabular}

Table 2. Number of measurements available on 22 May 1992, at 1015 UT and for the day.

\begin{tabular}{|c|c|c|c|c|c|c|c|c|}
\cline { 2 - 9 } \multicolumn{1}{c|}{} & $\mathrm{BP}$ & $\mathrm{SO} 2$ & $\mathrm{SO} 2$ day & $\mathrm{NO} 2$ & $\mathrm{NO} 2$ day & $\mathrm{NO}$ & NO day & AF day \\
\hline $\mathrm{BP}$ & 1.00 & 0.99 & 1.00 & 1.00 & 1.00 & 1.00 & 1.00 & 0.76 \\
$\mathrm{SO} 2$ & 0.99 & 1.00 & 0.89 & 0.96 & 1.00 & 0.89 & 1.00 & N/A \\
\hline $\mathrm{SO} 2$ day & 1.00 & 0.89 & 1.00 & 0.65 & 0.84 & 0.50 & 0.80 & N/A \\
\hline $\mathrm{NO} 2$ & 1.00 & 0.96 & 0.65 & 1.00 & 0.96 & 0.98 & 0.98 & N/A \\
\hline NO2 day & 1.00 & 1.00 & 0.84 & 0.96 & 1.00 & 0.89 & 1.00 & N/A \\
\hline NO & 1.00 & 0.89 & 0.50 & 0.98 & 0.89 & 1.00 & 0.92 & N/A \\
\hline NO day & 1.00 & 1.00 & 0.80 & 0.98 & 1.00 & 0.92 & 1.00 & N/A \\
\hline AF day & 0.76 & N/A & N/A & N/A & N/A & N/A & N/A & 1.00 \\
\hline
\end{tabular}

Table 3. Correlation coefficients between pollutant measurements. Strong acidity (AF) is not measured in the same sites than the other parameters except BP.

The day of 22 May 1992 was a sunny day with clear sky. Pollution level was below critical levels. A Landsat image was acquired on that day at 1017 UT. A sample of this image is presented in figure 1 . The size is $15.36 \mathrm{~km}$, with a pixel size of $30 \mathrm{~m}$. The channel TM4 (at $0.8 \mu$ ) reveals the patterns of the streets and roads in the city (in dark tones). The airport is clearly seen in the South. Also appearing dark are the Loire river and two other rivers flowing into the Loire, from the North and from the Southeast. Nantes is obviously organised along these water ways. Light tones are mostly related to vegetation as several large parks are found in Nantes.

\section{COMPARISON BETWEEN AIR QUALITY MEASUREMENTS AND SATELLITE OBSERVATIONS}

The processing of the Landsat data was minimal. No calibration was applied. Looking into the physics of the problem, it appears obvious that the spatial resolution of the sensor has a strong influence upon the results. Hence no resampling of the signal was performed prior to the analysis. The TM6 pixel is $120 \mathrm{~m}$ in size.

Locations of pollution measuring stations were reported onto a digital map of the streets of Nantes. This map was superimposed onto the Landsat image. The TM4 channel (figure 1) was used for that processing because it clearly exhibits the network of streets. From TM6 were extracted the digital counts corresponding to the stations as well as their vicinity (radius of about $100 \mathrm{~m}$ ). The difficulty of extracting the relevant value was larger than expected. The error 
in location is not the largest one. The main difficulty is caused by the exact location of the measuring instrument which can be, for example, on a wall in a narrow street, or within a park within a patchwork of lawns and trees. To each station was attached a score summarising the quality of the extraction. The local heterogeneity of the digital counts and the vicinity of the measuring instrument have been taken into account to establish that score.

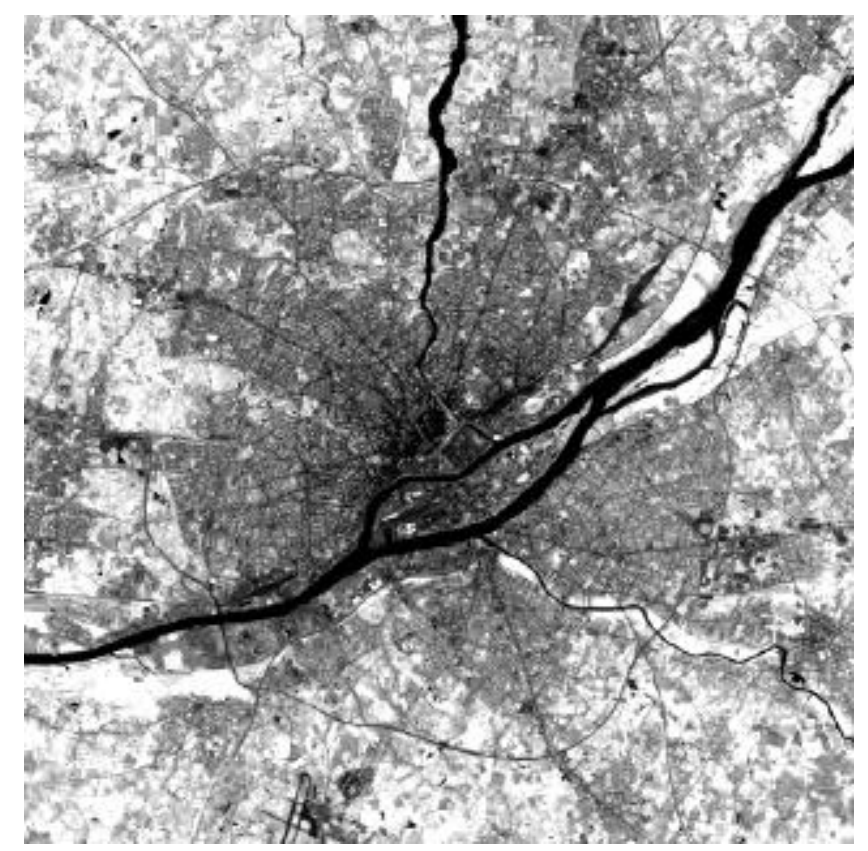

Figure 1. Sample of an image of the city of Nantes, acquired by the satellite Landsat (TM-4, at $0.8 \mu$ ), on 22 May 1992. The network of streets is fairly seen in dark tones, as well as the Loire river and the airport in the South. (C) Eurimage, reproduced with permission.

Once the 14 TM6 digital counts have been extracted, they were compared with the measurements of the various pollutants, either on a daily basis or for the time of image acquisition by the satellite. An apparent temperature was computed with the following formula:

TM6 apparent temperature $=170$ - TM6 digital count

This formula is arbitrary and simply intends to obtain values which increase with the apparent temperature and not the opposite, like the TM6 digital count. The units are arbitrary. As long as equation (1) holds, the following results are valid. Table 4 gives the correlation coefficient between the pollutant measurements and the apparent temperatures. The coefficients corresponding to the confidence level of $95 \%$ are also given. This table has been computed by removing several stations from the initial list of 14 , as discussed above. A very high and significant correlation (0.95) is found between the BP and the apparent temperature. Figure 2 shows the BP versus the apparent temperature. A high correlation coefficient (0.86) is also found with the daily averaged SO2, but with a lower confidence level (85\%). It should be noted that the link between apparent temperatures and the SO2 is larger on a daily basis than on an instant basis (correlation is only 0.67). This is also true for the NO2 and NO; however the correlations are weak in both cases. Finally table 4 indicates that the correlation is also weak for the AF.

We conclude that only the $\mathrm{BP}$ is highly correlated to the apparent temperature. It is likely that the SO2 is correlated to the apparent temperature but the number of measurements is too small to being conclusive.

Analysis of the TM 6 image reveals that the change in temperature from a polluted area to an unpolluted one of similar type and land use, may be several degrees Celsius. Such differences are large. Several explanations can be provided 
which may not be related to pollution. The energy budget of the surface is very sophisticated mechanism. For example, changes in humidity or air temperature or land use (e.g. vegetation) may induce similar differences.

\begin{tabular}{|c|cc|c|c|c|c|c|c|}
\hline & BP & SO2 & SO2 day & NO2 & NO2 day & NO & NO day & AF day \\
\hline $\begin{array}{c}\text { Correlation } \\
\text { coefficient }\end{array}$ & 0.95 & 0.67 & 0.86 & 0.43 & 0.67 & 0.26 & 0.61 & 0.68 \\
\hline $\begin{array}{c}\text { Number of } \\
\text { values }\end{array}$ & 6 & 4 & 4 & 4 & 4 & 3 & 3 & 9 \\
\hline $\begin{array}{c}\text { Conf. level } \\
95 \%\end{array}$ & 0.81 & 0.95 & 0.95 & 0.95 & 0.95 & 0.997 & 0.997 & 0.67 \\
\hline
\end{tabular}

Table 4. Correlation coefficients between the pollutant measurements and the apparent temperatures measured in TM6. The second line gives the number of values. The third one provides the correlation coefficient for which the confidence level of $95 \%$ is attained for this number of values.

\section{BP versus TM6}

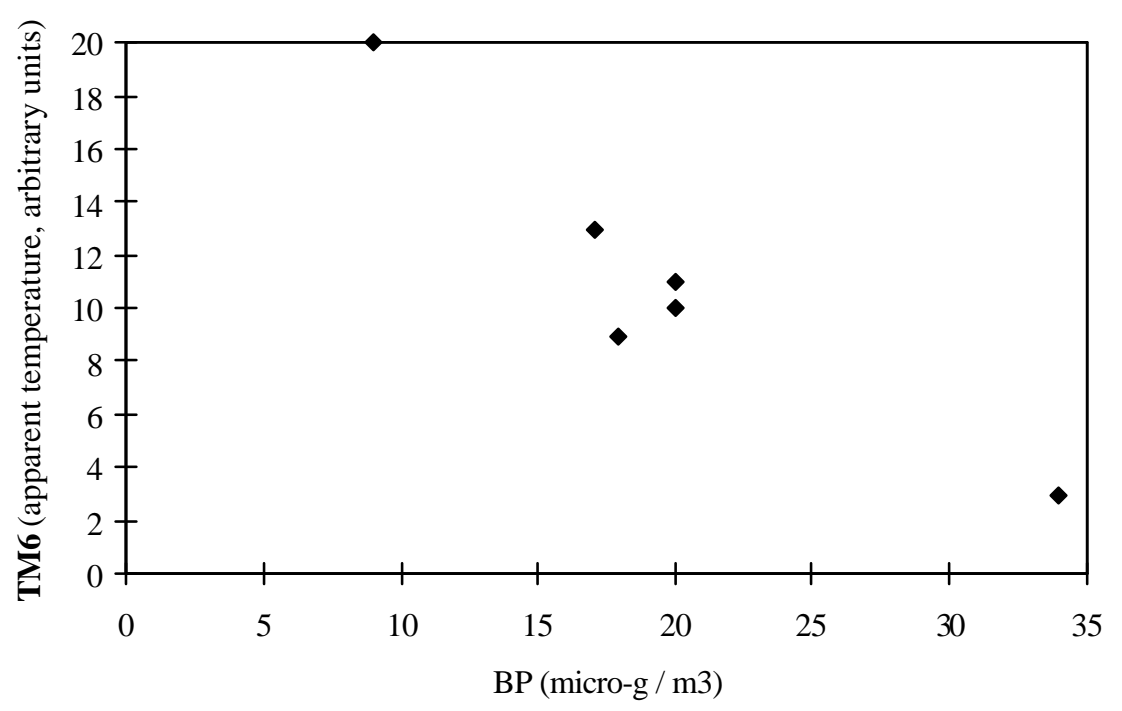

Figure 2. Correlation between black particulates for 22 May $1992\left(\mathrm{BP}\right.$, in $\left.\mu \mathrm{g} / \mathrm{m}^{3}\right)$ and apparent temperature observed by the satellite. Unit is arbitrary, 1 unit corresponds to a step of $0.5^{\circ} \mathrm{C}$.

\section{DISCUSSION}

Relationship between the BP and the apparent temperature

Nevertheless if we assume that the pollution plays a major role in the pattern of temperature, two processes occur simultaneously which explain the relationship between the BP and the apparent temperature. The appearance of a pollution layer (more absorption and scattering) results in a decrease of the atmospheric transmission factor. On the one hand, this decay leads to a decrease of the solar radiation impinging on ground. The solar heating is thus decreased as well as the resulting temperature of the surface. Hence the emitted radiance is lower, and the signal sensed by the satellite is lower. On the other hand, this pollution layer absorbs as well the emitted radiance, causing a depletion of the upward radiance. This is the second process explaining the relationship. Both processes contribute to the decrease of the apparent temperature as the pollution increases. 
The magnitudes of these processes have been assessed by the means of numerical models, namely ALLAN (Gaz de France) for heat transfer and MODTRAN for atmospheric optics. For the first process, we assumed two pixels having the same temperature at $3 \mathrm{~h}$ in the morning, that is that of the air $\left(10^{\circ} \mathrm{C}\right)$. These pixels are covered by asphalt; the depth for heat diffusion is limited to $1 \mathrm{~m}$ (Jaloustre-Audouin 1998). The sky was assumed clear. The changes in surface temperature were computed assuming standard meteorological conditions, from 0300 UT to 1000 UT. The pollution observed in the ground measurements is highly correlated to the vehicle traffic. To simulate this effect, we have depleted the incoming solar irradiance over the second pixel during the period of traffic, that is 0700 UT to 1000 UT ( $9 \mathrm{~h}$ to $12 \mathrm{~h}$ in French summer time). The magnitude of the depletion was adjusted so that the difference in temperature at $1000 \mathrm{UT}$ between both pixels was $3{ }^{\circ} \mathrm{C}$, which is approximately what is observed in the image. It turns out that the necessary amount of depletion is a fairly large fraction of the incoming irradiance. This is equivalent to saying that the pollutants cast a noticeable shadow over the polluted pixel. This is obviously exaggerated. We conclude that this process is not the major responsible of the changes in apparent temperatures.

For the second process, we ran several MODTRAN simulations, using standard profiles for summer and winter at mid-latitudes. A decrease in the visibility from 50 to $40 \mathrm{~km}$ produced the expected change in apparent temperature. This corresponds to a decrease in the transmittance of about $10 \%$. An increase in the BP can lead to similar values, due to their scattering properties. We conclude that the second process may be partly responsible for the pollutants to be sensed in TM6 channel, and that changes in atmospheric transmittance should be taken into account.

The authors are aware of the limitations of the discussion which is not a demonstration. As already discussed, the physics is very complex with many interactions. Only two of the possible cause mechanisms have been briefly investigated. One should also consider the fact that vehicles, being made in metal, have a very low emissivity. A large density of cars in a TM 6 pixel may lead to a depletion of the apparent temperature. More numerical simulations are necessary as well as more case studies.

\section{Influence of the size of the pixel}

The pixel size of TM6 is $120 \mathrm{~m}$, which is rather large for a proper description of European cities. The value borne by a pixel is a non-linear average of the radiances emitted by the very elements composing the pixel: pavement, streets, buildings (wall, roof, different materials, etc.), trees, other vegetation, vehicles, etc. This value does not necessarily represent the value measured by the station, which is usually like a pin-point, particularly if this station is located close to the border of the pixel. In other words, given the size of the features in a city, a pixel of $120 \mathrm{~m}$ may be not relevant to study the air quality. The larger the pixel, the greater the discrepancy between satellite-derived temperature (or any other parameter) and the ground measurements. The magnitude of the discrepancy is probably a function of how great the pollution is and how large its spatial extension is. This influence of the size of the pixel is in agreement with the above-mentioned studies as well as this one. The better results were obtained when using the highest spatial res olution.

For a further analysis of this influence, a method was applied to synthesise a TM6-HR image having a resolution of 30 m. It makes use of the wavelet transform (Ranchin and Wald 1993) and of the ARSIS concept; it is detailed in, for example, Ranchin and Wald (1997) and Ranchin et al. (1998). This method draws information out from the other TM channels at $30 \mathrm{~m}$ and inject small structures into the original TM6 image. The TM6-HR pixel size is $30 \mathrm{~m}$, but the actual resolution is between 30 and $120 \mathrm{~m}$. Table 5 shows the correlation coefficients obtained with the TM6-HR, and compared with those of TM6. As for TM6, the correlations with the instantaneous values of NO2, NO and AF are weak. The correlations with daily values are larger. For the BP and daily values of SO2 and AF, TM6 performs better than TM6-HR. On the contrary, for daily values of NO2 and NO, TM6-HR performs the best.

These results are interpreted as follows. The BP, SO2 and AF are more uniformly distributed in space than the other pollutants. Hence, a slight increase in resolution may not lead into a increase of the correlation. Furthermore, TM6-HR is the result of a synthesis process, and contains some noise which degrades the correlations. As for NO2 and NO, they experience chemical transformations into respectively NO and ozone (O3), and NO2. These transformations are fast, and changes in these pollutants occur rapidly. These pollutants are also easily advected. It follows that the variability in space and time of these pollutants is large, much larger than that of the BP and SO2. Therefore, a high spatial resolution should provide better correlation. 


\begin{tabular}{|c|c|c|c|c|c|c|c|c|c|}
\hline & BP & SO2 & SO2 day & NO2 & NO2 day & NO & NO day & AF & AF day \\
\hline TM6 & 0.95 & 0.67 & 0.86 & 0.43 & 0.67 & 0.26 & 0.61 & 0.25 & 0.68 \\
\hline TM6-HR & 0.87 & 0.61 & 0.77 & 0.49 & 0.72 & 0.32 & 0.66 & 0.31 & 0.49 \\
\hline
\end{tabular}

Table 5. Influence of the size of the pixel. Correlation coefficients between the pollutant measurements and the apparent temperatures measured in TM6 and TM6-HR.

\section{MAPPING THE CONCENTRATION OF BLACK PARTICULATES}

If we admit that changes in apparent temperature are mostly due to the presence of pollutants, it is worth computing a linear relationship between the BP and the TM6 digital counts, by a least-square regression (see table 6 for the regression parameters):

$$
\mathrm{BP}=1.38 * \text { TM6 digital counts }-200.25
$$

\begin{tabular}{|c|c|}
\hline Correlation coefficient & 0.95 \\
\hline Regression line. Slope & 1.38 \\
\hline Regression line. Offset & -200.25 \\
\hline
\end{tabular}

\begin{tabular}{|c|c|}
\hline Explained variance (\%) & 0.89 \\
\hline Error on slope & $0.24(17 \%)$ \\
\hline Error on offset & $37.77(19 \%)$ \\
\hline
\end{tabular}

Table 6. Parameters of the regression line between the BP and the digital counts measured in TM6. BP = slope * TM6 + offset

This relationship can be applied to any pixel of the TM6 image in order to derive the BP and hence to map the concentration of the BP in Nantes. This was performed onto the six TM6 digital counts not used to establish the relationship. The discrepancies between the observed and the predicted values are displayed in table 7 . The bias is very high and there is an overestimation of the BP: relative value is $-55 \%$. The rms is also high, the relative value is $78 \%$.

\begin{tabular}{|c|c|}
\cline { 2 - 2 } \multicolumn{1}{c|}{} & 6 values \\
\hline Mean value for the BP $\left(\right.$ in $\left.\mu \mathrm{g} / \mathrm{m}^{3}\right)$ & 13 \\
\hline Bias (observed - predicted) $\left(\right.$ in $\left.\mu \mathrm{g} / \mathrm{m}^{3}\right)$ & $-7(-55 \%)$ \\
\hline $\mathrm{rms}$ (in $\left.\mu \mathrm{g} / \mathrm{m}^{3}\right)$ & $10(78 \%)$ \\
\hline Standard -deviation (in $\left.\mu \mathrm{g} / \mathrm{m}^{3}\right)$ & $7(56 \%)$ \\
\hline
\end{tabular}

Table 7. Discrepancy between observed values of the BP and predicted values from satellite observations. Predictions are made using the regression line defined in table 6 . The model is applied to the six stations not used to establish the regression.

We conclude that the mapping of the BP is possible using the TM6 image. This mapping is not very accurate, the relative rms is about $80 \%$. A fusion of the estimated map and of the few measuring stations will probably improve the results (see the work of Beyer and Wald 1996 or D'Agostino and Zelenka 1992, for example). For future works, account should be taken of the network of the streets, which constitutes the network for the ventilation of the city, along which the BP disperse. This would also ensure that the emissivity of the surface is more or less the same, and would avoid prediction of large concentrations of BP because of a very low emissivity. Given the high variability in space of the pollutants, it is likely that, despite the inaccuracy of the above relationship, such a mapping would provide more accurate prediction than an interpolation method making use of only the measuring stations.

Obviously satellite data should not be used for alert purposes. If further studies prove the significance of a relationship between satellite data and pollutants, they would be used for analysis and study of the patterns of pollutants in relation to other parameters, including urban morphology and street networks.

\section{CONCLUSIONS}

This study adds evidence on the correlation between satellite measurements in thermal infrared and air quality parameters. It has been shown that the BP is highly correlated to the apparent temperature. It is likely that the SO2 is 
correlated to the apparent temperature but the number of measurements is too small to be conclusive. Further studies are needed to definitely assess the relationship between satellite observations and air quality and its causes.

Numerical simulations show that the depletion of the upward radiance by the pollutant layer (decrease of visibility) may partly explain why pollutants are sensed in the TM6 channel. Since this depletion is caused by scattering and not by gaseous absorption, a major consequence is that the pollutants should affect visible and infrared bands and not only the thermal infrared channel. A study is underway to investigate whether pollutants can also be observed in these channels. In turn, if positive, this would demonstrate the importance of the depletion of the radiance emitted by the surface by pollutants. A practical consequence is that any classification of a city using remotely sensed data should take into account the pollution level since it would be equivalent to local depletions of the atmospheric visibility.

This study also shows that a high spatial resolution is highly desirable for the detection of some pollutants. The mapping of the BP is possible using the TM6 image. Paving the way in this domain, the study assesses the accuracy of the mapping, which is presently low. Methods for quality improvements have been discussed and further studies are needed.

Though of limited ext ension - one city, one date - the present study clearly demonstrates that satellite observations of apparent temperature of a city bring unique information about air quality, which cannot be attained by conventional means.

\section{ACKNOWLEDGEMENTS}

The authors are indebted to Eurimage which kindly provided the Landsat image, and to Loirestu'Air which kindly supplied the in situ data. The authors are grateful to Giulia Abbate, Karine Jaloustre, Eberhard Parlow and Roberta Ruffo for fruitful discussions and help. Special thanks are due to Luc Lavrilleux for giving us understanding of air quality. Remarks from the referees greatly improved this article.

\section{REFERENCES}

Alnaser W. E., 1995. Impact of Kuwait's oil-fire smoke cloud on the sky of Bahrain. Solar Energy, 54, 6, 387-396.

Beyer H., Wald L., 1996. Merging ground-measurements and satellite-derived data for the construction of global radiation map. In : Proceedings of the conference "Fusion of Earth data: merging point measurements, raster maps and remotely sensed images", Cannes, France, February 6-8, 1996, Thierry Ranchin and Lucien Wald Editors, published by SEE/URISCA, Nice, France, p. 37-43, 1996.

Brivio P. A., Genovese G., Massari S., Mileo N., Saura G., Zilioli E., 1995. Atmospheric pollution and satellite remotely sensed surface temperature in metropolitan areas. In EARSeL Advances in Remote Sensing 'pollution monitoring and geographical information systems', pp. 40-46, EARSeL, 2, avenue Rapp, Paris, France, 185 p.

Carnahan W. H., Larson R. C., 1990. An analysis of an urban heat sink. Remote Sensing of Environment, 33, 65-71.

D'Agostino V., Zelenka A., 1992. Estimating solar global irradiance by integration of satellite and network data: the cokriging approach. Science de la Terre, Série Informatique, 31, 461-465.

Dousset B., 1991. Surface temperature statistics over Los Angeles: the influence of land use. In Proceedings IGARSS'91, IEEE Catalog Number 91CH2971-0, 367-371.

Dousset B., Flament P., Bernstein R., 1993. Los Angeles fires seen from space. EOS Transactions, 74, 3, 33-38.

Eliasson I., 1992. Infrared thermography and urban patterns. International Journal of Remote Sensing, 13, 5, 869-879.

Finzi G., Lechi G. M., 1991. Landsat images of urban air pollution in stable meteorological conditions. Il Nuovo Cimento, 14C(5), 433-443.

Gallo K. P., McNab A. L., Karl T. R., Brown J. F., Hood J. J., Tarpley J. D., 1993. The use of vegetation index for assessment of the urban heat island effect. International Journal of Remote Sensing, 14, 11, 2223-2230.

Gaussorgues G., 1989. La thermographie infrarouge. $3^{\text {ème }}$ édition, Technique et Documentation Lavoisier, Paris, France, 560 p., 24 planches.

Henry J. A., Dicks S. E., Wetterquist O. F., Roguski S. J., 1989. Comparison of satellite, ground-based, and modelling techniques for analyzing the urban heat island. Photogrammetric Engineering and Remote Sensing, 55, 69-76. 
Jaloustre-Audouin K., 1998. SPIRou : synthèse de paysages en infrarouge par modélisation physique des échanges à la surface. Thèse de Doctorat, Université de Nice - Sophia Antipolis, France, 164 p.

Kim, H. H., 1992. Urban heat island. International Journal of Remote Sensing, 13(12), 2319-2336.

Le H.-Y., 1993. An application of NOAA AVHRR thermal data to the study of urban heat islands. Atmospheric Environment, Part B, 27, 1, 1-13.

Loirestu'Air, 1995. La pollution de l'air à Nantes et dans l'estuaire de la Loire en 1994. Report from Loirestu'Air, Nantes, France, $121 \mathrm{p}$.

McLellan A., 1973. Remote sensing of atmospheric turbidity variations by satellite. Journal of Spacecrafts and Rockets, 10, 11, 743-747.

McMichael A. J., Haines A., Slooff R., Kovats S. editors, 1996. Climate change and human health, World Health Organization, Geneva, Switzerland, 297 p.

Mestayer P., Anquetin S., 1995. Climatology of cities. In: Diffusion and transport of pollutants in atmospheric mesoscale flow fields, pp. 165-190, Gyr A. and Rys F.-S. Editors, ERCOFTAC Series, Kluwer Academic Publishers, 217 p.

Poli U., Pignatoro F., Rocchi V., Bracco L., 1994. Study of the heat island over the city of Rome from Landsat-TM satellite in relation with urban air pollution. In: Remote sensing - From research to operational applications in the new Europe, pp. 413-422, R. Vaughan Ed., Springer Hungarica, 442 p.

Price J. C., 1979. Assessment of the urban heat island effect through the use of satellite data. Monthly Weather Review, 107, 1554-1557.

Quattrochi D. A., Ridd M. K., 1994. Measurements and analysis of thermal energy responses from discrete urban surfaces using remote sensing data. International Journal of Remote Sensing, 15(10), 1991-2022.

Ranchin T., Wald L., 1993. The wavelet transform for the analysis of remotely sensed images. International Journal of Remote Sensing, 14(3), 615-619.

Ranchin T., Wald L., 1997. Data fusion of remotely sensed images using the wavelet transform : the ARSIS solution. In : Proceedings, SPIE Annual Meeting, Internatinal Symposium on Optical Science, Engineering and Instrumentation, San Diego, California, USA, 30 July - 1 August 1997 : Wavelet Applications in signal and Image Processing V, Akram Aldroubi, Andrew F. Laine, Michael A. Unser Chairs/Editors, SPIE vol. 3169, ISSN 0277-786X, p. 272-280, 1997.

Ranchin T., Wald L., Mangolini M., 1998. Improving spatial resolution of images by means of sensor fusion. A general solution: the ARSIS method. In:Remote Sensing and Urban Analysis. Edited by J.-P. Donnay and M. Barnsley. To be published by Taylor \& Francis, London, GISDATA Series ${ }^{\circ} 5$.

Roth M., Oke T. R., 1989. Satellite-derived urban heat islands from three coastal cities and the utility of such data in urban climatology. International Journal of Remote Sensing, 10, 1699-1720.

Sifakis N. I., Bildgen P., Gilg J.-P., 1992. Utilisation du canal 6 (thermique) de Thematic Mapper pour la localisation de nuages de pollution atmosphérique. Application à la région d'Athènes (Grèce). Pollution Atmosphérique, 34, 133, 96107.

Terjung W., O' Rourke P., 1980. Influence of physical structures on urban energy budgets. Boundary-Layer Meteorology, 19, 421-439.

Todhunter P., Terjung W., 1988. Intercomparison of three urban climate models. Boundary-Layer Meteorology ,42, $181-205$. 